tain chain. To every observer, indeed, this must be obvious, Two reasons have been adduced in explanation- $\mathrm{I}$. That the glaciers have been smaller from the cold of the glacial period not having extended over Italy, as indicated by the absence of the reindeer and other sub-arctic species from the drift ; 2 . That denudation has been enormous. In spite of the southern exposure it hardly appears probable that there could have been sufficient difference in the size of the northern and southern glaciers to cause this contrast, as long as the glacial period lasted, for the vapour-laden winds from the sea must have deposited much of their moisture on the southern slopes as nnow. But, as the ice-age passed away, the southern aspect of the Alps would doubtless be freed from its influence sooner than the northern, and bence, while snow and ice reigned in the latter area, the regions south of the mountains underwent denudation, probably, for a vast period. I would therefore suggest that the comparatively small amount of glacial débris on the southern side of the Alps may arise from that region having been exposed for a much longer time to sub-aërial waste, and in particular to the floods caused by the more rapid melting of the snows on the southern slopes of the mountains.

so, Old Square, Birmingham, December I6

\section{Electric Lighting}

IN the Procecdings of the Philosophical Society of Manchester $\mathrm{Mr}$. Wilde has described a new electric lamp, in which the carbons are placed parallel to each other, as in a Jablochlioff candle, but without any insulating material. It may not be apparent to all why the arc always locates itself at the extremity of the pair of carbons, and this, as Mr. Wilde observes, whether the lamp be erect or inverted. The explanation is that the current in each carbon repels the electric arc exactly as the current in the mercury-troughs repels the connecting cross-wire in a well-known experiment of Ampère. In Wilde's candle we have two fixed conductors, the carbons, and a movable conductor, the arc. Since the current in the arc and the current in either carbon are one from the other towards the point of junction of that carbon with the arc, the arc must be repelled by the carbon. One cannot but be surprised that Ampère's experiment did not suggest the discovery made by Mr. Wilde, that the insulating material might with advantage be omitted in Jablochkoff 's candle.

4, Westminster Chambers, December I 2

\section{The Reproduction of the Eel}

THE time of spawning and the differences between the sexes of the common eel has been hitherto unknowis. Last year for the first time in this country eels (Anguilla bustoniensis) containing eggs were found, December 31, by Mr. Edwards, at New Bedford, Mass, as stated by Mr. Putnam in the Proceedings of the Boston Society of Natural History. From observations on eels brought me at Providence, R.I. it appears that eels spawn here in salt or brackish water from October to the end of November, as I have found several eels containing eggs which seemed nearly ripe, the ovary being full and large. To-day on examining the testis of a male cel 17 inches long, the mothercells and sperm-cells were found, the latter numerous and lively, from $\frac{1}{3000}$ to $\frac{1}{20000}$ inch in diameter. The eggs were white, just large enough to be distinguished by the naked eye, measuring a little less than $\frac{1}{2} \mathrm{~mm}$. in diameter. The females are larger than the males, with the belly white, while the males are easily distinguishable by the dark bellies and a narrow silvery or golden median stripe.

Laboratory of Brown University, U.S., November 27

\section{AERATED BREAD}

SOME remarks upon aerated bread which were made by Dr. B. W. Richardson at the recent general meeting of the company working Dr. Dauglish's patents require examination. Now it is noteworthy how imperfect our knowledge of the chemistry of the millproducts from the cereal grains still remains. Without such knowledge we are not in a position to dogmatise as to the exact nutritive values of different kinds of bread. As I pointed out in a previous article on "Real Brown
Bread," the statement that whole wheaten meal, bran, pollard, \&c., contain more nitrogen, and therefore more flesh-formers than fine flour, rests upon no certain basis of analytical fact. And if it were proved that all the nitrogen of the most nitrogenous of mill-products does really exist in what are called albuminoids or fleshformers, we cannot ignore the presence of much indigestible fibrous material in bran and pollard, material which is not only non-nutritive itself, but which locks up in an inaccessible form much of the real nutrient substances associated with it. Thus a sample of wheaten bran, or rather, fine pollard, may refuse to give up to the boiling dilute acid and alkali used in fibre-determinations more than six-sevenths of its nitrogenous matter; and it can hardly be expected that the secretions of the alimentary canal will prove successful in withdrawing a larger proportion. Indeed, the analysis of the residues of such foods after having been submitted to the digestive process, has confirmed this expectation in the case of the human subject. Moreover, while a not inconsiderable part of the albuminoid matters of the outer coverings of the grain thus escapes digestion from its mechanical condition, there is good reason to believe that a further portion remains unabsorbed, by reason of the rather hurried passage of the branny particles through the digestive tract. And the same causes which operate to prevent a part of such flesh-formers as exist in the bran from being utilised, affect also and in a similar way the useful mineral substances which abound in the coarser mill-products, as well as the oil or fat which they contain.

Now let us see what are the distinctive advantages claimed for Dr. Dauglish's bread-making process by Dr. Richardson. It yields a bread which is said to be "perfectly clean, perfectly wholesome, and completely nutritious." As to the perfect cleanliness of this mechanical process for making bread there can be no question; it is immeasurably superior to the barbarous and old, but, as Dr. Richardson remarked, not "time-honoured system of kneading dough by the hands and feet of the workman." And we may agree, with almost equal confidence, in the statement that aerated bread is perfectly wholesome. The stream of pure water charged with carbonic acid gas vesiculates the dough, which has required neither alum, nor blue vitriol, nor lime-water, to check the irregular fermentation, and neutralise the sourness of nouldy or otherwise damaged or inferior flour. But, on the other hand, the adoption of the aerating process does not of itself necessarily exclude all adulterations of the bread: materials to whiten the loaf and to cause the retention of a larger percentage of water may still be used. As to the small loss of nutrient materials involved in the ordinary fermentation of dough, it hardly merits consideration. Perhaps Dr. Richardson alluded to it because it gave him an opportunity of having a fling at his old enemy, alcohol, of which it has been found that a newly-baked loaf, made by means of yeast, contains about 0.25 per cent. So that a man who eats twenty quartern loaves has therein consumed an amount of alcohol which is commonly contained in one bottle of port! But if there be no really serious loss of starch by conversion, first into sugar, and then into carbonic acid gas and alcohol, there can be no doubt that a number of altered products are present in a fermented loaf, and that these are less abundant and less variable in nature in aerated bread. But the presence in fermented bread of larger quantities of sugar, gum, and soluble starch than are found in aerated bread is not usually a disadvantage so far as the digestibility of the loaf is concerned. It is rather to the production of lactic acid and of nitrogenous ferments by the use of yeast or leaven that we should attribute the uncertain value of ordinary bread. The quality of the yeast, too, must not be left out of consideration, as some of our home and of our imported. supplies are by no means of a satisfactory character.

$$
{ }^{\prime} \text { See Natuke, vol. xviij, p } 229 .
$$


I may now discuss the third meritorious feature which Dr. Dauglish regarded as a conspicuous advantage possessed by his process-a view which is now endorsed by Dr. Richardson. We are told that "in brown bread, which contains the envelopes or coverings of the whole grain, the flesh-formers amount to Io per cent., and that, while it is possible to live upon brown bread, without any other food, the health suffers, and death finally ensues, on white bread alone." "The flesh-formers in white bread amount," we are told, "to 7 or 8 per cent." Now by the use of the aerating process; a light and palatable loaf may undoubtedly be readily made, either from the entire meal of crushed wheat, or from such meal from which nothing but the long or coarse bian has been excluded. Such a result cannot be secured with any degree of certainty when yeast is used. This is quite true. But it is not by any means an ascertained fact that brown bread or whole meal bread contains a larger proportion of flesh-formers than white bread from the same wheat. If we make no deduction on account of insoluble and inaccessible flesh-formers in the coverings of the grain, we shall have to make a very considerable deduction on account of nitrogenous matters which are not really albuminoid or flesh-forming, and which are extensirely present in the coats which form the main substance of pollard and sharps. We can hardly attribute flesh-forming properties to the "diastase," "cerealin," and other obscure nitrogenous ferments which we know to abound in the coarser mill products. Now these are the very bodies which the aerating process enables us to include in our bread without making it heavy, the very bodies whose presence contributes most largely to raise the percentage of assumed flesh-formers, from the 7 or 8 per cent. in white bread to the ro per cent. in real brown bread. Now, although we have no absolute method of distinguishing between the true flesh-forming nitrogenous bodies in food-stuffs and those whose value is at the best problematical, yet the "carbolic acid process" which I devised in 1873 , and which has latterly been attracting a good deal of attention, furnishes some instructive results when applied to the various mill products of the cereals. For instance. I found (in I 875) that pearl barley contains at least 92 per cent. of its nitrogen in the form of genuine coagulable albuminoids, but that "fine dust," consisting of the richest parts of the barley grains, though it contains three times as much nitrogen as pearl barley, does not contain twice as much unmistakable flesh-forming substance. A similar observation was made on comparing the coverings of the wheat grain with the flour -93 parts out of every 100 of nitrogen in ordinary wheaten flour being certainly in the form of flesh-producers, while the proportion in the entire bran sinks to an average of 72 , and sometimes touches a much lower figure. The same result has been obtained with a large number of food materials, in some succulent vegetables the albuminoid nitrogen not exceeding one-fifth of the whole.

It is evident, from the preceding considerations, that whatever be the nutritive or medicinal merits of wholemeal bread, it cannot be definitely stated to be a much richer food so far as flesh-formers are concerned, than white bread made from the flour of the same sample of wheat grain. If we deduct from the supposed to per cent. of flesh-formers in whole meal bread $\frac{1}{5}$ or 2 per cent. because of the existence of non-albuminoid nitrogen in the branny particles, and because of the indigestible condition of a small part of the true albuminoids, we leave but $\delta$ per cent. a proportion which does not greatly exceed the 7 or $7 \frac{1}{2}$ per cent. usually attributed to white wheaten bread.

On some future occasion I may have a few words to say, should the Editor of NATURE accord his permission, as to the bread question treated of in the "Dietaries of Prisons' Report," lately presented to Parliament.

A. H. CHuRCH

\section{ON THE COMBUSTION OF DIFFERENT KINDS OF FUEL}

$U R$ attention has been called to this subject on perusing a paper read before the American Institute of Mining Engineers. In this communication it is attempted to be proved, that the manner in which charcoal unites with oxygen in iron furnaces, explains its alleged superiority over mineral coal.

The question appears to us to involve considerations outside the mere technical limits of iron smelting. We therefore submit the following remarks, which have been prepared at our request, by a gentleman whose important researches on the economic application of fuel in the smelting of iron are known to all the world.-ED. NATURE.

Prof. John A. Church, of Columbus, states, in a recent publication, "that it is a well-known fact that under similar conditions a ton of pig-iron can be made from any ore with less fuel when charcoal is used than when coke or anthracite is employed for heating." He then discards, as untenable, all former explanations of this doctrine proceeding either from scientific or practical men, and maintains that "the highest carbon duty is given by the fuel which withdraws the most oxygen from the blast in a given time."

The professor afterwards proceeds to explain that charcoal, being highly porous, presents a more extended surface to the action of the oxygen than the more compact forms of carbon as it exists in coke or anthracite. $\mathrm{He}$ then considers the effect of what is designated in the paper as diluted oxygen on its way to the upper regions of the blast furnace.

In this latter statement with regard to free oxygen, it seems to be overlooked that whatever difficulty this gas may have in attacking dense carbon, there can be no reason why carbonic oxide, generated from coke or anthracite, should not be as easily burnt to the state of carbonic acid as the same carbonic oxide is burnt when formed by the combustion of charcoal.

If it could be shown that all the carbon consumed in the hearth of the blast furnace were in the condition of carbonic acid, then, no doubt, free oxygen might be expected there, but in the presence of so vast a volume of inflammable carbonic oxide in that region such a condition of things is scarcely possible.

It is unnecessary, however, to occupy space with merely speculative matter when actual analyses inform us that in a furnace using coke, not only is there no free oxygen at a very short distance from the tuyeres, but that there is no carbonic acid. In pcint of fact the whole of the gaseous carbon exists there in the form of carbonic oxide.

Admitting, then, the highest carbon duty to be dependent on the law laid down in the paper, it is clear that at a distance of two or three feet from the point where the blast enters, the conditions in this respect of a furnace burning charcoal or coke are the same.

Prof. Church quotes, in the course of his observations, the results obtained from two. furnaces, one using charcoal the other anthracite, and from these he infers that there is an "inherent difference" between the two kinds of fuel of 900 lbs. per ton of iron in favour of charcoal. This figure is a mighty one when it is considered that the charcoal actually consumed for each ton of pig is under I, 800 lbs.

Somewhat inconsistent with this conclusion is the instance quoted of a Lake Champlain furnace, where the consumption of anthracite has been reduced nearly 25 per cent. below that quantity which formed the basis upon which the "inherent difference" was estimated.

The paper further recommends as a reasonable consequence if the superiority of charcoal over coke, that iron manufacturers should, as far as possible, imitate the physical structure of the former in the produce of their 